\title{
AN EMPIRICAL STUDY OF THE PSYCHODYNAMICS OF SUICIDE: A PRELIMINARY REPORT
}

\author{
Susan E. Chance, M.A., ${ }^{1}$ Susan L. Reviere, M.A., James H. Rogers, Ph.D., ${ }^{1}$ Mark E. James, M.D., Salley Jessee, \\ M.D. ${ }^{3}$ Lisseth Rojas, M.A., ${ }^{4}$ Carrie A. Hatcher, B.A., ${ }^{5}$ and Nadine J. Kaslow, Ph.D. ${ }^{6 *}$
}

Preliminary results from a study of psychodynamic constructs are presented based on data from inpatients following a suicide attempt. The study examines the association between four psychodynamic constructs, severity of suicidal intent, and severity of depressive symptomatology in a sample of bospitalized suicide attempters. Higher levels of suicidal intent were associated with less differentiated self and object representations and less emotional investment in relationships. More severe depressive symptoms in suicide attempters were correlated with more self-targeted anger, less eternally directed anger, higber levels of shame and guilt, more affectively negative views of relationships, greater use of maladaptive and self-sacrificing defenses, and more impaired reality testing. These findings offer some preliminary empirical support for the validity of psychodynamic theories of suicidal bebavior. Depression 4:89-91 (1996). @ 1997 Wiley-Liss, Inc.

\section{INTRODUCTION}

$\mathbf{P}$ sychodynamic theorists posit that suicidal behavior is associated with: (1) self-directed anger, (2) pathological responses to object loss, (3) poorly integrated hostile introjects and few soothing introjects (pathological internal object relations), and (4) ego functioning disturbances in the form of borderline level defenses and impaired reality testing in response to loss. These constructs lack empirical testing and validation (Hendin, 1991).

In terms of self-directed anger, it has been suggested that suicidal people turn against themselves the destructive wishes felt toward a lost or disappointing object (Freud, 1917). Parts of the ego identified with the lost object become the target of sadistic wishes.

With regard to object loss, theorists posit that suicide may involve a fantasy of narcissistic reunion, serving to undo this separation (Hendin, 1991). Research reveals that people who experience early losses and painful separations are at increased risk for suicide (Cross and Hirschfield, 1986).

Object relations theory views suicide as an attempt to destroy bad internal objects. According to Kernberg (1975), suicide represents the superego's attempt to eliminate the bad self that results from the internalization of pathological interpersonal interactions. Maltsberger and Buie (1980) assert that suicidal people evidence poorly integrated hostile introjects and few soothing introjects. Thus, in response to nar- cissistic injuries, they are unable to self-soothe or turn to others for comfort.

Ego theorists assert that the primary defenses used by suicidal people include denial, splitting, idealization, introjection, regression, and repression (Apter et al., 1989). They also note that suicidal persons manifest impaired reality testing in response to abandonment or self-esteem loss.

This paper presents initial results from an empirical study examining the association between these four psychodynamic constructs, severity of suicidal intent, and severity of depressive symptoms in suicide attempters.

\footnotetext{
${ }^{1}$ Department of Psychiatry and Behavioral Sciences, Georgia State University, Atlanta, GA; ${ }^{2}$ PROMINA Windy Hill Hospital, Atlanta, Georgia; ${ }^{3}$ Emory University School of Medicine and Emory University Psychoanalytic Institute, Atlanta, Georgia; ${ }^{4}$ Derner Institute at Adelphi University, Garden City, New York; ${ }^{5}$ Department of Psychology, University of Michigan; ${ }^{6}$ Emory University School of Medicine, Atlanta, Georgia.
}

Contract grant sponsor: American Psychoanalytic Association Research Fund.

*Correspondence to: Nadine Kaslow, Ph.D., Emory University Department of Psychiatry and Behavioral Sciences, Grady Health System, 80 Butler Street SE, Atlanta, GA 30335.

Received for publication 24 June 1996; Revised 6 August 1996; Accepted 9 September 1996. 


\section{METHOD}

The sample was 46 females $(\mathrm{n}=32)$ and males $(\mathrm{n}=$ 14), Mean $_{\text {age }}=30.5(\mathrm{SD}=10.7)$, hospitalized at Grady Health System, a teaching affiliate of Emory University School of Medicine, that serves an urban, low income population. Most participants were African American (62\%). Patients with schizophrenia, bipolar disorder, organicity, or serious medical illnesses were excluded.

Participants, recruited within 1 week of hospitalization, provided written informed consent. Severity of suicidal intent was measured by the Suicide intent Scale (SIS) (Beck et al., 1979). Diagnoses were obtained from the Structured Clinical Interview for Diagnosis (SCID) (Spitzer et al., 1990). Other symptom measures were the Beck Depression Inventory (BDI) (Beck et al., 1961) and the Depression and Suicide Constellations of the Rorschach (Exner, 1993). To evaluate the self-directed anger hypothesis, the SelfTargeted Anger (STA) (Knopf et al., 1990, unpublished data), and Shame-Guilt (Gioella, unpublished manuscript) scales were used. To examine the loss hypothesis, demographic data were obtained about losses. Object representations were measured by the Hypervigilance Index of the Rorschach, the Object Relations Inventory (ORI) scored using the self-other differentiation scale (Diamond et al., 1990), and Thematic Apperception Test (TAT) with responses coded for complexity of human representations, affect-tone of relationships, capacity for emotional investment in relationships, and understanding of social causality (Westen et al., 1990). The Bond Defense Style Questionnaire (BDSQ) (Bond, 1984) and Rorschach ego structure measures (coping deficit index, schizophrenia index) assessed ego functioning.

\section{RESULTS}

Patients' primary Axis I disorders were depression ( $n=27,59 \%)$, substance use $(n=8,17 \%)$, adjustment $(n=9,20 \%)$, and other $(n=3,7 \%)$. Axis II diagnoses were: Cluster A, $7 \%(n=3)$; Cluster B, $33 \%(n=15)$; Cluster C, $9 \%(n=4)$; Personality Disorder NOS, $20 \%(n=9)$. Patients reported high levels of depression on the BDI $(M=23.5, \mathrm{SD}=12.9)$.

Correlational analyses revealed that those suicide attempters with higher levels of intent on the SIS reported more depressive symptoms on the BDI $(r=.27, P<.05)$, more prior attempts $(r=.29, P<.05)$, less differentiated self and object representations on the ORI $(r=-.29, P<$ $.05)$, and less emotional investment in relationships according to their TAT responses $(r=-.31, P<.05)$.

Attempters reporting high levels of depressive symptoms (BDI), endorsed more self-targeted anger $(r$ $=.32, P<.05)$ and less externally directed anger $(r=$ $-.32, P<.05)$ on the STA, more shame and guilt on the Shame-Guilt Scale $(r=.50, P<.001)$, more affectively negative representations of relationships in their TAT responses $(r=-.25, P<.05)$, more maladaptive $(r=.52, P<.01)$ and self-sacrificing $(r=.33$, $P<.05)$ defenses on the BDSQ, and more impaired reality testing according to their schizophrenia index on the Rorschach $(r=-.28, P<.05)$.

\section{DISCUSSION}

Preliminary findings support three psychodynamic constructs, particularly for those suicide attempters with either elevated levels of suicide intent or depressive symptoms. Attempters with greater intent endorsed more narcissistic and less mutual object relationships, and demonstrated less differentiated self and object representations. This finding is consistent with the hypothesis that suicidal behavior is associated with pathological internal object relations.

The self-directed aggression theory appears pertinent to depressed attempters, as they exhibit increased self-targeted anger and higher levels of shame and guilt. It is of note, however, that higher levels of suicide intent and depressive symptoms were associated with lower levels of externally directed anger in the present study, a finding contradictory to the research revealing that suicidal behavior is correlated with aggression and violence (e.g., van Praag et al., 1990), but consistent with early psychodynamic theories postulating that the rage and anger experienced by suicidal individuals is directed toward the self rather than toward others.

Depressed attempters used maladaptive action pattern and self-sacrificing defenses, which might make them prone to deflect aggression away from others and turn to self-destruction. They also have problems perceiving reality in a manner similar to that of most people. These findings offer support for dynamic theories indicating that depressed, suicidal people use primarily borderline level defenses and evidence reality testing problems, both of which are suggestive of ego functioning deficits.

Attempters with higher levels of suicide intent and/ or depressive symptoms did not report greater levels of object loss, raising questions about the utility of the object loss hypothesis. This finding should be examined more given the lack of a thorough measure of loss, and the discrepancy between these data and those from other researchers (Cross \& Hirschfield, 1986).

Findings must be interpreted cautiously given the small sample size, dearth of statistically significant findings in the predictive analyses, lack of cultural sensitivity of the measures, the broad and heterogeneous nature of the participants' Axis I and II diagnoses, and the lack of a control group. Future research needs to include more narrowly defined samples in terms of psychiatric diagnoses, and focus on comparisons of suicide and nonsuicide attempters in terms of self-directed aggression, object loss, internal object relations, and ego functioning. While data on the association between suicidal intent, severity of de- 
pressive symptoms, and the psychodynamic constructs hypothesized to be associated with suicidal behavior provide some empirical support regarding the utility of these hypotheses, a comparison of attempters and nonattempters is needed to substantiate or disprove these constructs.

Acknowledgments. The authors thank Lawrence Inderbitzin, M.D., for his comments on an earlier version of this manuscript. This study was funded by a grant from the American Psychoanalytic Association Research Fund.

\section{REFERENCES}

Apter A, Plutchik R, Sevy S, Korn M, Brown S, van Praag H (1989) Defense mechanisms in risk of suicide and risk of violence. Am J Psychiatry 146:1027-1031.

Beck AT, Ward CH, Mendelson M, Mock JE, Erbaugh J (1961) An inventory for measuring depression. Arch Gen Psychiatry 4:561-571.

Beck AT, Kovacs M, Weissman A (1979) Assessment of suicidal intention: The scale for suicide ideation. J Consult Clin Psychol 47:343-352.

Bond $M(1984 / 1986)$ Defense Style Questionnaire. In Valiant GE (ed): Empirical Studies of Ego Mechanisms of Defense. Washington DC: American Psychiatric Press.
Cross CK, Hirschfield RMA (1986) Psychosocial factors and suicidal behavior: Life events, early loss, and personality. Ann NY Acad Sci 487:77-89.

Diamond D, Kaslow N, Coonerty S, Blatt S (1990) Changes in separation individuation and intersubjectivity in long-term treatment. Psychoanal Psychol 7:363-397.

Exner JE (1993) The Rorschach: A Comprehensive System. New York: John Wiley

Freud S (1917/1957) Mourning and melancholia. In Complete Psychological Works, Standard Edition Volume 14. London: Hogarth Press.

Hendin H (1991) Psychodynamics of suicide, with particular reference to the young. Am J Psychiatry 148:1150-1158.

Kernberg O (1975) Borderline Conditions and Pathological Narcissism. New York: Jason Aronson.

Maltsberger JT, Buie DH (1980) The devices of suicide: Revenge, riddance, and rebirth. Int Rev Psychoanal 7:61-72.

Spitzer RL, Williams JBW, GIbbon M, First MB (1990) Structured Clinical Interview for DSM-III-R Patient Edition (SCID-P) and Structured Clinical Interview for DSM-III-R-Personality Disorders (SCID-II). Washington, DC: American Psychiatric Press.

van Praag HM, Plutchik R, Apter A (Eds) (1990) Violence and Suicidality: Perspectives in Clinical and Psychobiological Research. New York: Brunner/Mazel.

Western D, Lohr N, Silk KR, Gold L, Kerber K (1990) Object relations and social cognition in borderline, major depressives, and normals; A thematic apperception test analysis. Psychol Assess $2: 355-264$. 